\title{
Catastrophic Health Expenditure among Chronic Patients Attending Dessie Referral Hospital, Northeast Ethiopia
}

This article was published in the following Dove Press journal: ClinicoEconomics and Outcomes Research

\author{
Yohannes Shumet (iD) \\ Solomon Ahmed Mohammed (D) ${ }^{2}$ \\ Mesfin Haile Kahissay ${ }^{2}$ \\ Birhanu Demeke ${ }^{2}$ \\ 'Department of Pharmacy, College of \\ Medicine and Health Science, Debre \\ Tabor University, Debre Tabor, Ethiopia; \\ ${ }^{2}$ Department of Pharmacy, College of \\ Medicine and Health Science, Wollo \\ University, Dessie, Ethiopia
}

Background: Catastrophic health expenditure is health spending that is not covered by a health-care plan. These costs tend to escalate over time, due to chronic illnesses. Catastrophic health expenditure leads to decreased use of health services and poorer treatment outcomes. This study measured the extent of and factors associated with catastrophic health expenditure among chronically ill patients attending Dessie Referral Hospital in northeast Ethiopia.

Methods: An institution-based cross-sectional study design was used to quantify catastrophic health expenditure among 302 chronically ill patients from May 25, 2018 to June 30, 2018. A stratified sampling technique was used to select the study participants. Descriptive and inferential statistics were computed using SPSS 20.

Results: Catastrophic health expenditure was found in 194 (64.2\%, 95\% CI 58.8\%-70.5\%) of chronic patients. Costly service $(151,50 \%)$, transport $(104,34.4 \%)$, and pharmaceuticals $(189,62.6 \%)$ were the reasons for catastrophic health expenditure among chronic patients. Factors associated with catastrophic health expenditure were age $<30$ years (AOR 7.74, CI 0.94-63.62; $P=0.01$ ), patient monthly income $<$ Br1,068 (AOR 203.47, CI 34.72-41.70; $P=0$ ), being single (, AOR 0.2, CI 0.02-1.4; $P=0.04$ ), familymonthly income $<\mathrm{Br} 1,068$ (AOR 0.02, CI 0-0.47; $P=0$ ), laboratory examinations (, AOR 1.54, CI 0.23-10.41; $P=0.04$ ), and transport, food, and lodging (AOR 0.05, CI 0.00-0.52; $P=0.01$ ).

Conclusion: Two-thirds of chronic patients had catastrophic health expenditure. Starting and strengthening various health-insurance schemes will make chronic-care services more accessible and affordable.

Keywords: chronic illness, out-of-pocket, health expenditure

\section{Background}

Catastrophic health expenditure is health spending that is not covered by a healthcare plan, neither private health insurance nor a public health scheme. ${ }^{1}$ If the financing of health care becomes more dependent on out-of-pocket payments, the burden imposed on those who use the services regularly is higher. ${ }^{2}$

The proportion of households facing catastrophic health expenditure varies widely among countries. ${ }^{3}$ One in six American families with disabled or elderly members experience high out-of-pocket health-care spending. These costs tend to escalate over time, due to chronic illnesses. For low-income families, 25\% ospend $>5 \%$ of their total household income on medical care services. ${ }^{2}$ The proportion of Turkish households with catastrophic health expenditure was $0.6 \%$, and average out-of-pocket health payments were US\$7.36. ${ }^{4}$
Correspondence: Solomon Ahmed Mohammed

Tel +25I-9I-050-4378

Email ahmedsolomon2I@gmail.com 
Private catastrophic health expenditure accounts for $20 \%-60 \%$ of national health expenditure in most low- and middle-income countries while in most developed economies it accounts for only $15 \%-25 \%{ }^{5}$ In Bangladesh, the mean total of catastrophic health expenditure in 30 days was US\$27.66 per capita, corresponding to $20.26 \%$ of monthly per capita gross domestic product during the fiscal year 2009-2010. ${ }^{6}$ In India, the proportion of catastrophic health expenditure increased 2.24-fold between the years 1995-1996 (11.1\%) and 2014 (24.9\%). ${ }^{7}$

In Nigeria, $16.4 \%$ of households incur catastrophic health expenditure at a $10 \%$ threshold of total consumption expenditure. ${ }^{8}$ Catastrophic health expenditure drives $6 \%$ of Egyptian households to financial catastrophe. ${ }^{9}$ Each year, Kenyan households spend over a tenth of their budget on health-care payments. ${ }^{10}$ In most developing countries, the cost ofhealth expenditure is too high, and this tends to push a majority of the population who cannot afford it toward poverty. ${ }^{1}$ Although access to appropriate and affordable health care is crucial to achieve better health outcomes in Africa, access to health care remains low, especially among the poor. ${ }^{11}$

The level of disposable income earned by an individual or household and employment and education of an individual affect catastrophic health expenditure. ${ }^{5}$ Patients with social health insurance in South Korea ${ }^{12}$ have catastrophic expenditure more than their counterparts. However, research done in Nigeria ${ }^{13}$ and Vietnam ${ }^{14}$ showed that lack of health-insurance coverage was strongly associated with impoverishment. Households with increased family members with special diseases, ${ }^{13}$ elderly people, ${ }^{15}$ and geographic location of households are also potential determinants. ${ }^{16}$

Prescription drugs constitute the biggest share of out-ofpocket payments in the US, ${ }^{2}$ while medicine expenditure in low-income countries accounts for $>57 \%$ of outpatient outof-pocket costs at public facilities and over $45 \%$ of outpatient out-of-pocket costs at private facilities. ${ }^{17}$ Those who lived in urban areas spend double the amount on medicine (US \$24.06) of rural residents (US\$12.68) in Bangladesh. ${ }^{6}$ Transportcosts also amount to $12 \%$ of out-of-pocket treatment charges for outpatient services. ${ }^{17}$

Out-of-pocket payments for health-care services lead to decreased use of health services and catastrophic health expenditure. Reducing incidence of household catastrophic health expenditure is one of the objectives of health policy. Knowing the incidence and determinants of catastrophic health expenditure is the basis for developing effective health policies to address this problem. ${ }^{18}$ Therefore, this study measured the extentidentified determinants of catastrophic health expenditure among chronically ill patients attending in Dessie Referral Hospital, northeast Ethiopia.

\section{Methods}

\section{Study Area and Period}

This study was conducted in the town of Dessie, Amhara National Regional State, northeast Ethiopia from May 25, 2018 to June 30, 2018. Dessie is located $401 \mathrm{~km}$ from Addis Ababa. Dessie Referral Hospital is a large institution serving Dessie $(219,978)$ and the surrounding population (7 million).

\section{Study Design}

An institution-based cross-sectional study design was used.

\section{Study Population}

Subjects were chronically ill patients attending regular follow-ups at chronic-care units of Dessie Referral Hospital.

\section{Inclusion and Exclusion Criteria}

Chronic patients attending regular follow-ups during the study period and willing to participate in the study aged $\geq 18$ years were included. Chronic patients with communicable diseases receiving exempted services, seasonal cases, and hospitalized patients were excluded.

\section{Dependent Variable}

The dependent variable was catastrophic health expenditure. Measuring catastrophic health expenditure requires specification of the thresholds for household income or capacity to pay (nonfood expenditure), which household health expenditure should not exceed. Despite the two most commonly used measures being $10 \%$ of total household income ${ }^{19}$ and $40 \%$ of household capacity to pay, ${ }^{20}$ there is no consensus on these thresholds. ${ }^{21,22}$ Catastrophic health expenditure for chronic patients was estimated using household expenditure on chronic care $>10 \%$ of total household income.

\section{Independent Variables}

The independent variables were sociodemographic (sex, age, marital status, residence, education, household composition), socioeconomic (occupationand household income), and reasons for catastrophic health expenditure (health-service expenditure, nonmedical expenses, and outpatient and inpatient services). 


\section{Sample-Size Determination and Sampling Procedure}

The sample size was estimated by using a single population-proportion formula using $50 \%$ prevalence, $95 \%$ confidence level, and $5 \%$ tolerable sampling error. Since the source population was $<10,000$ (1,230 chronic cases), the sample size was adjusted to a total of 323 participants. Stratified sampling of patients (660 with diabetic mellitus and other hormonal problems, 300 cardiovascular system and chronic kidney problems, and 270 with central nervous system problems) followed by simple random sampling was used to select study participants. The response rate was $96.49 \%$. As such, 162 with diabetic mellitus and other hormonal problems, with 74 cardiovascular system and chronic kidney problems, and 66 with central nervous system problems were included.

\section{Data Collection and Quality Assurance}

A structured interviewer-administered questionnaire was employed to collect patient data patients by two nurses who had no working relationship with the hospital after recruiting and half-day training with the supervision of the principal investigators. The questionnaire included sociodemographic characteristics (sex, age, marital status, residence, education, and household composition), household income, direct health-service expenditure, nonmedical expenses, and outpatient and inpatient services. Health spending were assessed for various items, including registration, drugs, consultations, and diagnostic purposes. Data were pretested in $5 \%$ of the sample size, checked for completeness, accuracy, and consistency immediately after collection, and confidentiality was maintained. The reliability of the questionnaire was also checked by Cronbach's $\alpha(74 \%)$.

\section{Data Management and Analysis}

Data were entered and analyzed using SPSS 20. Variables with $P<0.25$ were transferred to multivariate logistic regression after binary logistic regression with $95 \%$ CIs. In logistic regression analyses, variables with $P<0.05$ were taken as statistically significant. Catastrophic healthexpenditure estimation requires measuring the extent to which health costs exceed different thresholds of household income or consumption expenditure. To categorize medical expenditure, household income was calculated, and $10 \%$ was taken as the reference point. Those patients with health expenditure $\geq 10 \%$ of their household's income were categorized as catastrophic. ${ }^{19,21,23}$ Sensitivity analysis of the magnitude of catastrophic health expenditure was applied using different thresholds.

\section{Operational Definitions}

Chronic illness was taken as a long-term health condition that may not have a cure.

Catastrophic health expenditure was defined as the mean value by which out-of-pocket expenditure on the illness as a percentage of total household expenditure exceeded the $10 \%$ threshold.

\section{Results}

There were 174 (57.6\%) male respondents aged 15-96 years (mean $46.05 \pm 15.59$ years, Table 1 ). Over a third (34.8\%) were 31-44 years. A majority of respondents were married (52.3\%) and urban dwellers (70.9\%), and $21.9 \%$ were diploma holders.

Amost a third (31.1\%) were private workers. Monthly incomes ranged from nil to $\mathrm{Br} 9,000$ birr a with mean of $\mathrm{Br} 2,002.9 \pm 1718.35$. With regard to family monthly income, income ranged $\mathrm{Br} 400-10,000$, with mean income of $\mathrm{Br} 3,567.18 \pm 2,300.72$ (Table 2).

Table I Sociodemographic characteristics of respondents $(n=302)$

\begin{tabular}{|c|c|c|c|}
\hline & & $\mathbf{n}$ & Percentage \\
\hline \multirow[t]{2}{*}{ Sex } & Male & 174 & 57.6 \\
\hline & Female & 128 & 42.4 \\
\hline \multirow[t]{4}{*}{ Age, years } & $<30$ & 48 & 15.9 \\
\hline & $31-44$ & 105 & 34.8 \\
\hline & $45-64$ & 97 & 32.1 \\
\hline & $>64$ & 52 & 17.2 \\
\hline \multirow[t]{2}{*}{ Residence } & Urban & 214 & 70.9 \\
\hline & Rural & 88 & 29.1 \\
\hline \multirow[t]{4}{*}{ Marital status } & Married & 158 & 52.3 \\
\hline & Single & 77 & 25.5 \\
\hline & Widowed & 41 & 13.6 \\
\hline & Divorced & 26 & 8.6 \\
\hline \multirow[t]{6}{*}{ Education } & Illiterate & 21 & 7 \\
\hline & Able to read and write & 50 & 16.6 \\
\hline & Elementary school & 70 & 23.2 \\
\hline & High school & 51 & 16.9 \\
\hline & Diploma & 66 & 21.9 \\
\hline & Degree & 44 & 14.5 \\
\hline
\end{tabular}


Table 2 Socioeconomic characteristics of respondents $(n=302)$

\begin{tabular}{|l|l|l|l|}
\hline \multicolumn{2}{|l|}{} & n & Percentage \\
\hline Occupation & Private & 94 & 31.1 \\
& Government & 64 & 21.2 \\
& Farmer & 64 & 21.2 \\
& Others* & 80 & 26.5 \\
\hline Monthly income of patient, $\mathrm{Br}$ & $<1,068$ & 126 & 41.7 \\
& $1,069-3,200$ & 118 & 39.1 \\
& $3,201-5,250$ & 42 & 13.9 \\
& $>5,250$ & 16 & 5.3 \\
\hline Monthly income of family, $\mathrm{Br}$ & $<1,068$ & 39 & 12.9 \\
& $1,069-3,200$ & 131 & 43.4 \\
& $3,20 I-5,250$ & 62 & 20.5 \\
& $>5,250$ & 70 & 23.2 \\
\hline
\end{tabular}

Note: *Laborers, servants, housekeepers.

Two-thirds (66.6\%) of patients had comorbid conditions. Costly service and absence of health insurance were the reasons for catastrophic health expenditure for 151 $(50 \%)$ and 65 (21.6\%), respectively. Costs incurred for transport (104, 34.4\%) and pharmaceuticals (189, 62.6\%) were also reasons for catastrophic health expenditure. Catastrophic health expenditure was found in 194 (64.2\%, 95\% CI 58.8\%-70.5\%) patients (Table 3). The magnitude of catastrophic health expenditure at 5\%, $15 \%$, and $20 \%$ thresholds was also estimated and 267 (88.41\%), 132 (43.7\%), and 112 (37.1\%) patients, respectively had catastrophic health expenditure.
Following univariate logistic regression analysis, sex, education, residence, and household numbers were not fitted to multivariate logistic regression analysis $(P<0.25$ ). Patients aged $<30$ years had 7.74 (AOR 7.74, 95\% CI 0.94-63.62) times the health expenditureof those aged $\geq 64$ years. Those whose monthly income was $<$ Br1,068 were 203 times more likely (AOR 203.47, 95\% CI 34.72-41.70) to have catastrophic health expenditure than those with monthly income $>\mathrm{Br} 5,250$. Single patients were $80 \%$ (AOR $0.2,95 \%$ CI $0.02-1.4$ ) less likely to have catastrophic health expenditure than divorced ones (Table 4).

Patients who paid for laboratory examinations had 1.54 (AOR: 1.54, 95\% CI 0.23-10.41)-fold the catastrophic health expenditure of patients who had a card. Patients who could afford transport, food, and lodging expenses were $95 \%$ (AOR $0.05,95 \%$ CI $0.00-0.52$ ) less likely to have catastrophic health expenditure than those with indirect medical costs (Table 5).

\section{Discussion}

Health spending measures the final consumption of healthcare goods and services, including personal health care and collective services. The present study identified the extent and determinants of catastrophic health expenditure among chronically ill patients attending Dessie Referral Hospital in northeast Ethiopia. The prevalence of

Table 3 Factors involved in out-of-pocket expenditure among respondents $(n=302)$

\begin{tabular}{|c|c|c|c|}
\hline & & $\mathbf{n}$ & Percentage \\
\hline \multirow[t]{4}{*}{ Reasons for out-of-pocket expenditure } & Absence of health-insurance scheme & 65 & 21.6 \\
\hline & Costly service & 151 & 50 \\
\hline & Lack of nearby health facility & 46 & 15.2 \\
\hline & Absence of health-insurance scheme and costly service & 40 & 13.2 \\
\hline \multirow[t]{4}{*}{ Direct medical costs } & Pharmaceuticals & 189 & 62.6 \\
\hline & Laboratory examinations & 26 & 8.6 \\
\hline & Drugs and laboratory & 29 & 9.6 \\
\hline & Physical examinations & 58 & 19.2 \\
\hline \multirow[t]{4}{*}{ Indirect medical costs } & Transport & 104 & 34.4 \\
\hline & Food and lodging & 7 & 2.3 \\
\hline & Transportn, food, and lodging & 96 & 31.8 \\
\hline & No indirect medical costs & 95 & 31.5 \\
\hline \multirow[t]{3}{*}{ Household members } & Fewer than two & 100 & 33.1 \\
\hline & Four to five & $|4|$ & 46.7 \\
\hline & Six or more & 61 & 20.2 \\
\hline \multirow[t]{2}{*}{ Comorbid illness } & No & 101 & 33.4 \\
\hline & Yes & 201 & 66.6 \\
\hline
\end{tabular}


Table 4 Sociodemographic and economic factors associated with catastrophic expenditure $(n=302)$

\begin{tabular}{|c|c|c|c|c|}
\hline & \multicolumn{2}{|c|}{ Catastrophic } & \multirow[t]{2}{*}{ COR $(95 \% \mathrm{Cl})$} & \multirow[t]{2}{*}{ AOR $(95 \% \mathrm{Cl})$} \\
\hline & Yes & No & & \\
\hline \multicolumn{5}{|l|}{ Age, years } \\
\hline$<30^{*}$ & $35(72.92)$ & $13(27.08)$ & $0.64(0.25-1.63)$ & $7.74(0.94-63.62)$ \\
\hline $31-44$ & $49(46.67)$ & $56(53.33)$ & $0.2(0.09-0.45)$ & $1.29(0.22-7.62)$ \\
\hline $45-64$ & $68(70.1)$ & $29(29.9)$ & $0.55(0.24-1.26)$ & $2.83(0.59-13.64)$ \\
\hline$>64$ & $42(80.77)$ & $10(19.23)$ & 1 & 1 \\
\hline \multicolumn{5}{|l|}{ Marital status } \\
\hline Married & $96(60.76)$ & $62(39.24)$ & $0.57(0.22-1.4)$ & $1.03(0.16-6.64)$ \\
\hline Single* & $42(54.55)$ & $35(45.45)$ & $0.44(0.16-1.17)$ & $0.2(0.02-1.4)$ \\
\hline Widowed & $4(9.76)$ & 37 (90.24) & $3.4(0.88-13.11)$ & $5.08(0.55-46.37)$ \\
\hline Divorced & $7(26.92)$ & $19(73.08)$ & 1 & 1 \\
\hline \multicolumn{5}{|l|}{ Occupation } \\
\hline Private & $34(36.17)$ & $60(63.83)$ & $0.09(0.04-0.19)$ & $0.587(0.13-2.58)$ \\
\hline Government & $57(89.06)$ & $7(10.94)$ & $1.29(0.47-3.56)$ & $13.49(1.07-170.14)$ \\
\hline Farmer & $34(53.13)$ & $30(46.88)$ & $0.18(0.08-0.4)$ & $0.2(0.04-0.99)$ \\
\hline Others** & $69(86.25)$ & II (13.75) & 1 & 1 \\
\hline \multicolumn{5}{|c|}{ Patient monthly income, $\mathrm{Br}$} \\
\hline$<1,068^{*}$ & 117 (92.86) & $9(7.14)$ & $195(23.06-16,48.73)$ & $203.47(34.72-41.7)$ \\
\hline $1,069-3,200$ & $65(55.08)$ & $53(44.92)$ & $18.39(2.35-143.83)$ & $59.92(5.11-702.61)$ \\
\hline $3,20 \mathrm{I}-5,250$ & II (26.19) & 31 (73.8I) & $5.32(0.62-45.14)$ & $7.25(0.62-84.04)$ \\
\hline$>5,250$ & I (6.25) & $15(93.75)$ & 1 & 1 \\
\hline \multicolumn{5}{|c|}{ Family monthly income } \\
\hline$<1,068^{*}$ & 34 (87.18) & $5(12.82)$ & $8.55(2.99-24.46)$ & $0.02(0-0.47)$ \\
\hline $1,069-3,200$ & $92(70.23)$ & $39(29.77)$ & $2.96(1.62-5.42)$ & $0.29(0.06-1.39)$ \\
\hline $3,201-5,250$ & 37 (59.68) & $25(40.32)$ & $1.86(0.93-3.72)$ & $0.82(0.23-2.88)$ \\
\hline$>5,250$ & 31 (44.29) & 39 (55.7I) & 1 & 1 \\
\hline
\end{tabular}

Notes: $* P<0.05$. **Laborers, servants, housekeepers.

Table 5 Factors associated with catastrophic expenditure $(n=302)$

\begin{tabular}{|c|c|c|c|c|}
\hline & \multicolumn{2}{|c|}{ Catastrophic } & \multirow[t]{2}{*}{ COR $(95 \% \mathrm{Cl})$} & \multirow[t]{2}{*}{ AOR $(95 \% \mathrm{Cl})$} \\
\hline & Yes & No & & \\
\hline \multicolumn{5}{|l|}{ Reasons for out-of-pocket expenditure } \\
\hline Absence of health insurance & $39(60)$ & $26(40)$ & $0.5(0.2-1.19)$ & $0.2(0.04-1.02)$ \\
\hline Costly service & $89(58.94)$ & $62(41.06)$ & $0.47(0.2 \mathrm{I}-\mathrm{I} .05)$ & $0.77(0.21-2.76)$ \\
\hline Lack of nearby health facility & $36(78.26)$ & $10(21.74)$ & $1.2(0.44-3.26)$ & $2.37(0.36-15.64)$ \\
\hline Absence of health insurance and costly service & $30(75)$ & $10(25)$ & I & I \\
\hline \multicolumn{5}{|l|}{ Direct medical costs } \\
\hline Pharmaceuticals & $127(67.2)$ & $62(32.8)$ & $0.92(0.48-1.73)$ & $1.25(0.42-3.65)$ \\
\hline Laboratory examinations* & $10(38.46)$ & $16(61.54)$ & $0.28(0.1-0.73)$ & $1.54(0.23-|0.4|)$ \\
\hline Drugs and laboratory & $17(58.62)$ & $12(4 \mid .38)$ & $0.63(0.25-1.6)$ & $0.04(0.05-0.43)$ \\
\hline Cards & $40(68.97)$ & $18(31.03)$ & I & 1 \\
\hline \multicolumn{5}{|l|}{ Indirect medical costs } \\
\hline Transport & $64(6 \mathrm{I} .54)$ & $40(38.46)$ & $1.29(0.73-2.28)$ & $0.8(0.28-2.28)$ \\
\hline Food & $3(42.86)$ & $4(57.14)$ & $0.6(0.12-2.86)$ & $3.21(0.33-30.39)$ \\
\hline Transport, food, and lodging* & 74 (77.89) & $2 I(22.11)$ & $2.85(1.52-5.36)$ & $0.05(0-0.52)$ \\
\hline No indirect medical costs & $53(55.21)$ & $43(44.79)$ & 1 & I \\
\hline
\end{tabular}

Note: $* P<0.05$. 
catastrophic health expenditure was $64.2 \% \quad(95 \%$ CI $58.8 \%-70.5 \%$ ). In Bangladesh, the mean total of catastrophic health expenditure in a month was United States dollar 27.66 which corresponds to $20.26 \%$ of the monthly per capita gross domestic product of the year 2009 to 2010 . $^{6}$ Out-of-pocket payments are a common way of paying for health in developing countries. ${ }^{24}$

The burden of noncommunicable diseases is growing. Chronic conditions require continuing care and health services that may impose a regressive cost burden on households. $^{23}$ The burden is more pronounced for those whose health-care needs are higher and who use such services frequently. ${ }^{2}$ Catastrophic health expenditure is where individuals and households pay for health care out of their own resources. ${ }^{25}$ It becomes catastrophic when out-of-pocket payments for health services consume a large portion of available income. ${ }^{26}$ These payments have differentimpacts on health outcomes, health-service utilization, and financial security. ${ }^{24}$

The present study found that those age $<30$ years were 7.74 times as likely (AOR 7.74, CI 0.94-63.62) to have catastrophic health expenditure as those aged $>64$ years. This finding was different from studies conducted in other countries. In the US, one in six households with elderly members experience high out-of-pocket health-care spending. ${ }^{2}$ Elderly people spend 2-2.6-fold more on medication than their nonelderly counterparts in South Korea. ${ }^{15}$ Although elderly patients with multiple morbid conditions are more vulnerable to polypharmacy, direct nonmedical costs are higher in younger age-groups. This could be an important reason for high catastrophic health expenditure.

Chronic patients with a monthly income $<\mathrm{Br} 1,068$ were 203.47 times as likely (AOR 203.47, CI 34.7241.7) to have of catastrophic out-of-pocket medical expenditure as those earning $>\operatorname{Br} 5,250$ monthly. There is an increasing burden of medical expenses in South Korea, where families on the lowest incomes are 16.375 times more likely to experience catastrophic health expenditure.27 This is in line with a study conducted in Bangladesh, where the lowest quintile of individuals spent $16.27 \%$ of their monthly household income, ${ }^{6}$ while in Kenya, for every shilling increase in monthly household income, catastrophic health expenditure rises by 0.25 shillings on average. $^{5}$

Numerous studies have examined the relationship between household income and extent of catastrophic health expenditure for health care, and there is no clear- cut relationship, as the relationship varies from country to country. ${ }^{16}$ In this study, those with monthly family income $<$ Br1,068 were $98 \%$ less likely (AOR 0.02 , CI $0-0.47$ ) to have catastrophic health expenditure than those with monthly family income $>\mathrm{Br} 5,250$. However, the relationship between household size and catastrophic health expenditure was found to be statistically insignificant in this study. A case study in Kurdistan indicated that households that had multiple family members with special diseases were almost 5.5 times as likely to face catastrophic health expenditure as those with only one patient. ${ }^{13}$ Families with members that have any health problem are also twice as likely to spend a high portion of their income on health services. ${ }^{5}$

Access to health care remains low among the poor of Africa. ${ }^{11}$ Affordability and accessibility determine healthservice utilization in Africa. These people abstain from using essential health services, due to the increasing demand for health expenditure. ${ }^{28}$ Expenditure becomes financially catastrophic when it endangers a family's ability to maintain its standard of living. ${ }^{24}$ In addition to financial shock, households are often faced with income loss if affected members are working adults. ${ }^{26}$ As a result, many households are pushed into poverty due to catastrophic health expenditure. $^{29}$

In this study, patients' education was not found to be significantly associated with catastrophic health expenditure. This contrasts with a study done in Kenya where for every incremental month of occupation duration, catastrophic health expenditure decreased by 705.574 shillings. ${ }^{5}$ Better education has been found to increase the probability of earning more and the ability to acquire skills and knowledge to make informed choices on healthrelated matters. An educated household may make more effective use of modern medicine and is less likely to incur large expenditure. On the other hand, illiterate patients have weaker occupational and economic conditions, so they spend more of their money on health. ${ }^{13}$

The residence of chronic patients had a statistically nonsignificant relationship with catastrophic health expenditure in this study. Urban patients spent more than twice as much money on medicine as rural residents in Bangladesh, and rural inhabitants with lower socioeconomic status had a greater burden of catastrophic health expenditure (18.25\% of household income) than urban inhabitants $(14.28 \%)^{6}$ This is due to the fact that rural areas are far from cities. Unless things get complicated, 
most of the chronic rural patients seek services at nearby primary health-care units.

Single patients were $80 \%$ (AOR $0.2,95 \%$ CI $0.02-1.4$ ) less likely to have catastrophic health expenditure than divorced ones. A negative relationship between widowed patients and catastrophic health expenditure (AOR -0.29 , $\mathrm{CL}-0.69$ to 0.09 ) has been reported. ${ }^{28}$ Marital status is one of the reasons for further exacerbation of chronic disease conditions. Married peoples tend to be physically and mentally healthier, due to increased social support. Divorce is associated with greater disruptive behavior, higher rates of depressed mood, lower self-esteem, and emotional distress. This is associated with negative health outcomes and accelerates medical expenditure. ${ }^{30}$

Despite lack of health-insurance coverage being a nonsignificant determinant of impoverishment, 65 (21.6\%) patients had catastrophic health expenditure due to the absence of health insurance. This is in line with findings from studies in Vietnam ${ }^{14}$ and Nigeria ${ }^{5}$ that support the finding that lack of health insurance is strongly associated with impoverishment. Households in which patients do not have insurance are also $44 \%$ more likely to pay for catastrophic health expenditure than those with supplementary insurance. ${ }^{13}$ On the other hand, people enrolled with social health insurance have more catastrophic health expenditure than thosenot covered by social health insurance in China. ${ }^{12}$

Financial protection allows improving access to healthcare services, regardless of patients' ability to pay. ${ }^{29}$ Households and individuals who pay out of pocket for health-care services are vulnerable to incur catastrophic health expenditure, which exacerbates their level of poverty. ${ }^{14}$ The impact of health care-financing systems on the welfare of households is particularly important to reduce out-of-pocket payments and improve access to health-care services. ${ }^{31}$

Direct medical costs were significantly $(P=0.01)$ associated with catastrophic health expenditure in this study. Patients who had laboratory examinations had 1.54 (AOR 1.54, 95\% CI 0.23-10.41)-fold the catastrophic health expenditure of patients who paid for physical examinations. For every shilling increase in household costs of medical services, catastrophic health expenditure reduces by 0.211 shillings in Kenya. ${ }^{5}$ Depending on the type of chronic disease, medical costs differ in terms of amount and health outcome. ${ }^{27}$ Medicines account for $>57 \%$ of outpatient out-of-pocket expenses at public facilities and $>45 \%$ of outpatient out-of-pocket expenses at private facilities. ${ }^{17}$ In the US, $28 \%$ of low-income households spend $>10 \%$ of their disposable income on health services, ${ }^{2}$ and out-of-pocket payment for medical services is also very high in most developing countries. ${ }^{18}$ Chronic conditions require lifelong medication, and hence out-ofpocket costs are burdensome and a cause of inadequate medication use, leading to medication nonadherence. ${ }^{15}$

With regard to the relationship between indirect costs of medical services and catastrophic health expenditure, patients who had transport, food, and lodging expenses were $95 \%$ less likely (AOR $0.05,95 \%$ CI $0-0.52$ ) to have catastrophic health expenditure than those with any indirect medical costs. In low-income countries, catastrophic health expenditure for transport is $12 \%$ of treatment charges for outpatient services ${ }^{17}$ while the odds of food costs to result in catastrophic medical expenditure are 3.21 times less likely (AOR 3.21, CI 0.33-30.39) than absence of nonmedical costs. This is different from a study conducted in Kenya, where the odds of food costs to result in catastrophic medical expenditure were 0.069 times lower than absence of nonmedical costs. ${ }^{5}$ Direct nonmedical costs are expenditure as the result of an illness, not involved in the direct purchasing of medical services. These may include such expenditure as travel, lodging, and home services. ${ }^{32}$ Younger patients might prioritize quality of services and not worry about the cost.

Currently, chronic diseases are emerging in Ethiopia in both rural and urban dwellers. Each chronic disease has its own burden on patients' monthly income, and this study highlighted the major determinants of catastrophic health expenditure for chronic diseases, assisting health policymakers and health managers in prioritization of scarce health resources and designing interventions. However, the crosssectional nature of this study might make it harder to establish a temporal relationship. Even though we minimized the estimation error by helping the patients in their recall efforts, the measures of annual household income relied on selfreported information. This may have introduced recall bias. The sample was restricted to patients who sought care in a designated hospital. However, many patients might not choose to seek care, due to perceived financial barriers. This probably led to underestimation of the incidence and affects the generalizability of the findings. Moreover, the sample analyzed in this study can only reflect part of health spending of households: it is possible that other family members utilized health services in other hospitals.

\section{Conclusion}

Two-thirds of chronic patients had catastrophic health expenditure. Factors associated with catastrophic health 
expenditure were age $<30$ years, monthly patient income $<\mathrm{Br} 1,068$, being single, monthly family income $<\mathrm{Br} 1,068$, laboratory examinations, and transport, food, and lodging expenses of the patient. The government should start to strengthen various health-insurance schemes to make chronic care services more accessible and affordable.

\section{Data Sharing Statement}

The data sets are available from the corresponding author upon reasonable request.

\section{Ethics Consideration}

Ethics approval was obtained from the ethics review committee of the College of Medicine and Health Sciences, Wollo University (WU Phar/220/09). Informed consent was obtained from study participants, and confidentiality was maintained. Verbal informed consent was approved by the ethics review committee, and this study was conducted in accordance with the Declaration of Helsinki.

\section{Acknowledgment}

The authors would like to acknowledge the Department of Pharmacy, College of Medicine and Health Sciences, Wollo University.

\section{Author Contributions}

All authors made a significant contribution to the work reported, whether in the conception, study design, execution, acquisition of data, data analysis and interpretation, or in all these areas, took part in drafting, revising, or critically reviewing the article, gave final approval to the version to be published, have agreed on the journal to which the article has been submitted, and agree to be accountable for all aspects of the work.

\section{Funding}

There is no funding to report.

\section{Disclosure}

The authors declare that they have no potential conflicts of interest for this work.

\section{References}

1. Merlis M. Out of Pocket Spending for Health Services. A Continuing Source of Financial Insecurity. commonwealth fund; 2014.

2. Jessica B, Cunningham P, Bernard DM. Financial burden of health care. $J$ Health Affairs. 2008;27:188-195. doi:10.1377/hlthaff. 27.1.188
3. Xu K, Evans DB, Kawabata K, Zeramdini R, Klavus J, Murray CJ. Household catastrophic health expenditure: a multicountry analysis. Lancet. 2003;362(9378):111-117. doi:10.1016/S0140-6736(03)13861-5

4. Yardim MS, Cilingiroglu N, Yardim N. Catastrophic health expenditure and impoverishment in Turkey. Health Policy (New York). 2010;94(1):26-33. doi:10.1016/j.healthpol.2009.08.006

5. Okello NO, Njeru A. Factors affecting out-of-pocket medical expenditure among out patients in hospitals in Nairobi county. Int J Sci Res Publ. 2015;5.

6. Mahumud RA, Sarker AR, Sultana M, Islam Z, Khan J, Morton A. Distribution and determinants of out-of-pocket healthcare expenditures in Bangladesh. J Prev Med Public Health. 2017;50:91-99. doi:10.3961/jpmph.16.089

7. Pandey A, Ploubidis GB, Clarke L, Dandona L. Trends in catastrophic health expenditure in India: 1993 to 2014. Bull World Health Organ. 2018;96(1):18. doi:10.2471/BLT.17.191759

8. Aregbeshola BS, Khan SM. Out-of-pocket payments, catastrophic health expenditure and poverty among households in Nigeria 2010. Int $J$ Health Policy Manag. 2018;7(9):798. doi:10.15171/ ijhpm.2018.19

9. Rashad AS, Sharaf MF. Catastrophic and impoverishing effects of out-of-pocket health expenditure: new evidence from Egypt. Am J Econ. 2015;5(5):526-533.

10. Chuma J, Maina T. Catastrophic health care spending and impoverishment in Kenya. BMC Health Serv Res. 2012;12(1):413. doi:10.1186/1472-6963-12-413

11. Felix Masiye OK, Kaonga O. Determinants of healthcare utilisation and out-of-pocket payments in the context of free public primary healthcare in Zambia. Int J Health Policy Manag. 2016;5:693-703. doi:10.15171/ijhpm.2016.65

12. Zhonghua Wang X, Chen M. Social health insurance, healthcare utilization, and costs in middle-aged and elderly community-dwelling adults in China. Int J Equity Health. 2018.

13. Ghobad Moradi HS, Piroozi B, Qanbari L, Farshadi S. Catastrophic health expenditure among households with members with special diseases: a case study in Kurdistan. Med J Islam Repub Iran. 2017.

14. Van Minh HXTB, Xuan Tran B. Assessing the household financial burden associated with chronic non-communicable diseases in a rural district of Vietnam. Glob Health Action. 2012;5:18892. doi:10.3402/ gha.v5i0.18892

15. Eun-Park JWK, Eui-Kyung L, Young-Ho J, Sylvia P. Out-of-pocket medication expenditure burden of elderly Koreans with chronic conditions. Int J Gerontol. 2014.

16. Ajantha S, Samaratunge R. Paterns and determinants of out of pocket health care expenditure in Sri Lanka. Health Policy Plan. 2016;31:970-983. doi:10.1093/heapol/czw021

17. Priyanka Saksena R. Health services utilization and out-of-pocket expenditure at public and private facilities in low-income countries. World Health Rep. 2010.

18. Li W, Xu L, Legge D, et al. Factors affecting catastrophic health expenditure and impoverishment from medical expenses in China. Bull World Health Organ. 2012;90:664-671. doi:10.2471/ BLT.12.102178

19. Puteh S, Almualm Y. Catastrophic health expenditure among developing countries. Health Syst Policy Res. 2017;4:1.

20. Zhang X, Xu Q, Guo X, et al. Catastrophic health expenditure: a comparative study between hypertensive patients with and without complication in rural Shandong, China. BMC Public Health. 2020;20:1-3. doi:10.1186/s12889-020-08662-0

21. Zhou C, Long Q, Chen J, et al. Factors that determine catastrophic expenditure for tuberculosis care: a patient survey in China. Infect Dis Poverty. 2016;5(1):6. doi:10.1186/s40249-016-0100-6

22. Ranson MK. Reduction of catastrophic health care expenditures by a community-based health insurance scheme in Gujarat, India: current experiences and challenges. Bull World Health Organ. 2002;80:613621. 
23. Shewa Negsh B. Out of pocket expenditures among hypertensive patients and their households who Visit Public Hospitals in Addis Ababa, Ethiopia, 2016. Health Econ Outcome Res. 2016.

24. Akalu T. Examining out of pocket payments for maternal health in rural Ethiopia: paradox of free health care un-affordability. Ethiop $J$ Health Dev. 2012.

25. Xu K, Evans DB, Carrin G, Aguilar-Rivera AM, Musgrove P, Evans T. Protecting Households from catastrophic health Spending. J Health Affairs. 2007;26:972-983. doi:10.1377/hlthaff.26.4.972

26. Buigut E. Catastrophic health expenditure and its determinants in Kenya slum communities. Int J Equity Health. 2015.

27. Choi JW, Choi JW, Kim JH, Yoo KB, Park EC. Association between chronic disease and catastrophic health expenditure in Korea. BMC Health Serv Res. 2015.

28. Brinda EM, Andrés AR, Andrés RA, Enemark U. Correlates of outof-pocket and catastrophic health expenditures in Tanzania: results from a national household survey. BMC Int Health Hum Rights. 2014;14. doi:10.1186/1472-698X-14-5
29. Aregbeshola BS, Khan SM. Determinants of impoverishment due to out of pocket payments in Nigeria. J Ayub Med Coll Abbottabad. 2017;29.

30. Sbarra DA. Divorce and health: current trends and future directions. Psychosom Med. 2015;77(3):227. doi:10.1097/PSY.00000000000 00168

31. Chukwuemeka Umeh FF. Inequitable access to health care by the poor in community-based health insurance programs: a review of studies from low- and middle-income countries. Global Health. 2017;299-314.

32. Tanaka E, Hoshi D, Igarashi A, et al. Analysis of direct medical and nonmedical costs for care of rheumatoid arthritis patients using the large cohort database, IORRA. Modern Rheumatol. 2013;23(4):742751. doi:10.3109/s10165-012-0729-3
ClinicoEconomics and Outcomes Research

\section{Publish your work in this journal}

ClinicoEconomics and Outcomes Research is an international, peerreviewed open-access journal focusing on Health Technology Assessment, Pharmacoeconomics and Outcomes Research in the areas of diagnosis, medical devices, and clinical, surgical and pharmacologica intervention. The economic impact of health policy and health systems
Dovepress

organization also constitute important areas of coverage. The manuscript management system is completely online and includes a very quick and fair peer-review system, which is all easy to use. Visit $\mathrm{http}: / / \mathrm{www}$.dovepress.com/testimonials.php to read real quotes from published authors. 